\title{
PARTICIPAÇÃO JUVENIL E ESCOLA: OS JOVENS ESTÃO FORA DE CENA?
}

\author{
CARMEM ZELI DE VARGAS GIL*
}

\begin{abstract}
RESUMO
Por muito tempo, a participação juvenil ficou restrita à esfera das instituições clássicas e os partidos políticos de esquerda problematizaram o tema da participação democrática, mas o ator juvenil por excelência, foi sempre o movimento estudantil. Ampliar a compreensão desses processos, talvez ajude a diminuir o distanciamento entre a escola e os jovens, evidenciando que a apatia e o desinteresse possa ser uma busca por outros contextos educativos. Este texto, pautado em alguns estudos de pesquisadores que têm produzido conhecimento sobre o tema da participação juvenil, aponta diferentes contornos que ampliam a visão tradicional da participação político partidária. É tarefa dos professores, especialmente os de História, estarem atentos a tais questões, compreendendo que os jovens possuem saberes gestados em diferentes espaços educativos, o que implica renovar conteúdos e métodos de ensino. O marco teórico dessa reflexão parte do entendimento da participação juvenil nos escritos de Rosana Reguillo, Leslie Serna, José Antônio Pérez Islas, Regina Novais e Helena Abramo, e busca compreender as diferentes formas, conteúdos e processos de mobilização dos jovens contemporâneos. $\mathrm{O}$ conceito de juventudes se apóia na investigação sociológica de Marília Sposito, Mario Margulis, José Machado Pais e Alberto Melucci, tendo em vista articular as definições conceituais de juventudes com as de participação, e relacionar essas discussões com a escola. As idéias aqui reunidas pretendem instigar discussões e debates entre jovens e educadores, buscando ressignificar os sentidos atribuídos às ações coletivas juvenis na contemporaneidade.
\end{abstract}

PALAVRAS CHAVE: PARTICIPAÇÃO JUVENIL, AÇÕES COLETIVAS, JUVENTUDES

* Doutora em Educação, professora da Faculdade de Educação da UFRGS, Brasil. E-Mail: carmemz.gil@gmail.com.br. 


\title{
PARTICIPACIÓN JUVENIL Y ESCUELA
}

\begin{abstract}
RESUMEN
Por mucho tiempo la participación juvenil quedó restringida a la esfera de las instituciones clásicas, y los partidos políticos de izquierda problematizaron el tema de la participación democrática, pero el actor juvenil por excelencia, fue siempre el movimiento estudiantil. Ampliar la comprensión de esos procesos, tal vez ayude a reducir la distancia entre la escuela y los jóvenes, evidenciando que la apatía y el desinterés puede ser una búsqueda para otros entornos educativos. Este texto, con base en algunos estudios de investigadores que han producido conocimientos sobre el tema de la participación juvenil, señala diferentes contornos que amplían la visión tradicional de la participación política partidaria. Es tarea de los docentes, especialmente de los de historia, estar atentos a estas cuestiones, comprendiendo que los jóvenes poseen conocimientos gestados en diferentes espacios educativos, lo que implica renovar contenidos y métodos de enseñanza. El marco teórico de esta reflexión parte del entendimiento de la participación juvenil en los escritos de Rosana Reguillo, Leslie Serna, José Antonio Pérez Islas, Regina Helena Abramo y Novais, y busca comprender las diferentes formas, contenidos y procesos de movilización de los jóvenes contemporáneos. El concepto de juventudes se apoya en la investigación sociológica de Marília Sposito, Mario Margulis, José Machado Pais y Alberto Melucci, con el fin de articular las definiciones conceptuales de juventudes con las de participación, y relacionar esas discusiones con la escuela. Las ideas aquí reunidas pretenden propiciar discusiones y debates entre jóvenes y educadores, tratando de reformular los significados y sentidos atribuidos a las acciones colectivas juveniles en la época contemporánea.
\end{abstract}

\section{PALABRAS CLAVE: PARTICIPACIÓN JUVENIL, ACCIONES COLECTIVAS, JUVENTUDES}

\section{YOUTH PARTICIPATION AND SCHOOL}

\begin{abstract}
Traditionally, juvenile participation was restricted to the sphere of classical institutions and leftist political parties, which made the theme of democratic participation problematic. However, the juvenile actor of excellence was always the center of the student movement. To amplify the comprehension of these processes, it might be helpful to diminish the distance between school and young people, showing that apathy and disinterest can be a search for other educational contexts. This text, guided by the studies of researchers that have produced knowledge about juvenile participation, points to different profiles which amplify the traditional point of view of political party participation. It is the mission of teachers, especially History teachers, to be aware of such questions, understanding that youth pursues knowledge acquired in different educational spaces, which implies the renovation of content and educational methods. The theoretical mark of this reflection comes from the understanding of juvenile participation in the writings of Rosana Reguillo, Leslie Sema, José Antônio Pérez Islas, Regina Novais and Helena Abramo, and attempts to comprehend the different forms, content and processes of mobilization of contemporary youth. The concept of youths is based upon the sociological investigation of Marília Sposito, Mario Margulis, José Machado Pais and Alberto Melucci, with the objective of articulating the conceptual definitions of the youth with those of participation, and relating these discussions to school. The ideas collected here are meant to instigate discussions and debates between the youth and educators, looking to reframe the meanings attributed to collective juvenile actions found in contemporary society.
\end{abstract}




\section{ANÚnCIOS}

A JUVENTUDE TEM SIDO objeto de estudos sob diferentes perspectivas. Abordagens sociológicas, psicológicas, pedagógicas, antropológicas, entre outras, analisam mudanças físicas, emocionais e comportamentais que ocorrem neste momento da vida. Muitos estudos sociológicos voltam-se para problemas comuns da juventude, como abuso de álcool e drogas, delinquiência, gravidez, percalços na vida escolar, entre outros. Eles associam a juventude à noção de crise, irresponsabilidade e problema social, carente de políticas públicas. No entanto, também é tarefa importante abordar os jovens na normalidade do seu cotidiano, fato que talvez contribua para ampliar a compreensão de sua condição de aluno.

Alberto Melucci, ${ }^{1}$ em seus estudos, apresenta alguns motivos para estudar a juventude. Segundo ele: «Desafiando a noção dominante do tempo, os adolescentes anunciam para o resto da sociedade que outras dimensões da experiência humana são possíveis» (1997:11). Ainda, nas palavras do autor:

Os movimentos juvenis, feministas, ecológicos, étnico-nacionais, pacifistas não têm somente colocado em cena novos atores conflituais, formas de ação e problemas estranhos à tradição de lutas do capitalismo industrial; eles têm colocado no primeiro plano a inadequação das formas tradicionais de representação política para colher de maneira eficaz as questões emergentes (Melucci, 2001:95).

1 Situado entre a Psicologia e a Sociologia, Alberto Melucci é um dos autores que contribuiu para uma abordagem dos movimentos sociais centrada na complexidade, na atitude reflexiva da ação humana, tecendo uma interpretação menos catastrófica de processos ainda inconclusos. Suas reflexões sobre jovens são fruto de longos anos de trabalho clínico, consultas e psicoterapia com adolescentes, atividades de formação com professores que trabalham com jovens. Conduziu também pesquisas universitárias junto à Universidade de Trento e um projeto de pesquisa-intervenção, solicitado pelo Município de Milão, ao Centro Alia (coordenado por Anna Fabbrini, sua esposa). A pesquisa-intervenção incluiu encontros com grupos de adolescentes e levou à experiência piloto de criação de uma central de escuta de problemas cotidianos dos jovens. Essa central, única na Itália, permitiu, durante alguns meses, escutar os jovens assim como eles se contam. 
Melucci considera os jovens um laboratório dos tempos atuais. Como nômades do presente, pássaros migratórios, eles experimentam a provisoriedade de interesses, agregações e escolhas, a fragmentação e a diversidade; questionam a visibilidade do poder; reivindicam a autonomia para tomar decisões; exigem o direito ao silêncio, ao isolamento e à separação e percebem o presente como dimensão privilegiada da existência. São, portanto, o espelho retrovisor da sociedade, vivendo intensamente as questões do nosso tempo.

Este tema de intensa potência vem sendo mais estudado no Brasil nos últimos 15 anos. No presente artigo, as ideias sobre jovens, participação e educação são apresentadas no intuito de recolocá-las em debate, muito mais do que anunciar algum ineditismo. A participação juvenil em tempos de mudança e, por consequiência, os desdobramentos que tais questões possam ter na escola, serão os temas guias dessa reflexão.

Minha aproximação com o tema Juventudes ocorreu a partir da atuação como professora de escolas das redes pública e privada, tanto no ensino médio como universitário. As trocas e ações de parceria com jovens/alunos motivaram a aposta em relações positivas a respeito dos jovens. Por outro lado, o convívio com professores e estagiários do Curso de História colocaram-me frente aos dilemas da formação inicial e à ausência de expectativas positivas por parte de jovens estagiários sobre os alunos com os quais interagiam. Muitos são os rótulos atribuídos aos jovens: descompromissados, desinteressados, consumistas, não se ligam em nada... Por sua vez, também os alunos do Ensino Médio ressentem-se da falta de atenção às suas aspirações.

A convivência com jovens, como professora e pesquisadora, aguçou a curiosidade e o interesse de aproximar os temas juventude e ensino de História. A categoria juventude foi considerada nas narrativas históricas? A história política dos ditos "grandes homens" valorizava o pertencimento etário de seus protagonistas?

Uma rápida mirada para alguns momentos da História do Brasil, a partir da categoria juventude, evidencia que personalidades de destaque na História do Brasil, pelo envolvimento em atividades políticas ou culturais, não são lembradas como jovens, mesmo que estivessem situadas nessa faixa etária. Ao mesmo tempo, ainda que uma parcela dos jovens brasileiros tenha protagonizado diferentes movimentos históricos, nem sempre são reconhecidos como grupo singular nesses processos. 
Entretanto, em diferentes períodos, eles foram importantes atores de resistência e lutas democráticas. Por exemplo, os jovens abolicionistas brasileiros apresentaram as primeiras experiências políticas dos movimentos juvenis que se constituiriam mais tarde no Brasil. Eram, geralmente, graduados em Ciências Jurídicas, funcionários públicos ou atuavam na imprensa, vinculados, por laços de família, ao bloco agrário, predominantemente paulista. Entre moderados (consideravam a propriedade escrava legítima e, por isso, defendiam a abolição com indenizações) e radicais (a propriedade escrava era um roubo e pregavam a abolição total e imediata), ocupavam espaço no debate público que dividia a elite brasileira. Entre eles, estão: José do Patrocínio que, aos 25 anos, escrevia para os principais jornais do País; Joaquim Nabuco que, aos 20 anos, defendeu um escravo que se tornara assassino por pressão do sistema, atacou frontalmente o escravismo e sua tese passou a ser usada nos julgamentos posteriores de escravos que praticavam crime semelhante (Caccia-Bava e Costa, 2004).

Três movimentos foram expressões da participação de parcela dos jovens brasileiros na década de 20: a Semana da Arte Moderna, o Movimento Tenentista e o movimento político-partidário que resultou na criação do Partido Comunista. Neles, destacaram-se: Anita Malfatti, que realizou sua primeira exposição aos 23 anos; Luís Carlos Prestes, que, aos 24 anos, foi destaque no Movimento Tenentista; Plínio Salgado, que, aos 18 anos, criou, em São Paulo, o Partido Municipalista, em oposição ao governo de seu estado. Assim, os jovens também estão presentes nos movimentos da então denominada direita política. Inspirados na juventude fascista italiana e liderados por Plínio Salgado, fazem emergir o movimento dos Camisas Verdes, em cena desde os anos 30 no Brasil.

Com maior visibilidade nos currículos de História, os jovens da UNE tornaram suas algumas das lutas nacionais. Eles estiveram à frente da democratização da sociedade brasileira, denunciando a crise da universidade e os desmandos daqueles que fizeram a ditadura civilmilitar no Brasil. Nesse contexto, os estudantes aparecem como atores privilegiados nas mobilizações que integram a juventude brasileira às lutas operárias e camponesas. Hoje o cenário é outro, as bandeiras de lutas se diversificam e os atores são, cada vez mais, múltiplos e situados em movimentos efêmeros, que nascem e desaparecem conforme as demandas de mobilização.

Esse artigo refletirá sobre o reconhecimento dos jovens como sujeitos capazes de intervir nos processos históricos e sociais e questio- 
nará a abordagem da juventude como categoria social que necessita de políticas públicas e «controle» estatal, submetida à análise estatística e pensada como fase problemática da vida.

Se o ato educativo é um processo relacional, então o fazer pedagógico se torna mais difícil quando o outro é visto a partir de muitos estereótipos. Portanto, a visibilidade dos jovens em partidos, movimentos estudantis, ambientais, religiosos, étnicos, culturais, esportivos, virtuais e tantos outros, poderá contribuir para uma relação mais generosa entre dois grupos «condenados» a aprender juntos. Cabe, então, pensar: como isso incide sobre a relação educadores e jovens?

\section{OS ATORES JOVENS}

Alberto Melucci (1992) evocou a figura do «nômade» como metáfora das trajetórias dos jovens contemporâneos. Os «nômades do presente» avançam/exploram envoltos pelo provisório e pela incerteza que impõe o paradoxo da escolha: de um lado, a ampliação do espaço de autonomia individual e, de outro, o contexto perverso com o qual se defrontam jovens privados da materialidade do trabalho e do acesso a recursos para sua auto-realização, desprovidos do direito à juventude.

Parte dos jovens, em resposta às condições sociais de grande insegurança e de risco, encontra refúgio em projetos de curto prazo, que assumem o «presente estendido» (Leccardi, 2005) como área temporal de referência. Reagem ao «tempo curto» da sociedade da aceleração com projetos sui generis, que se expressam sobre arcos temporais mínimos e que, por isso mesmo, parecem extremamente maleáveis.

$\mathrm{O}$ «presente estendido» nega o futuro — não haverá trabalho, não haverá água potável, não haverá natureza, não haverá família- e impõe que tudo seja vivido no menor tempo possível, como uma ditadura do presente. Mas — como escreveu Victor Hugo, na obra Os miseráveis, «julgar-se-ia bem mais corretamente um homem por aquilo que ele sonha do que por aquilo que ele pensa»- os jovens destes tempos apontam para um futuro sonhado a partir do tempo presente, onde a possibilidade de decidir, participar, escolher e colocar idéias em prática fortalece o sentimento de pertencimento, a confiança em si como alguém capaz e a esperança de construir uma vida com projetos.

Nos diferentes contextos históricos e culturais, os jovens já foram a «geração cética» (Alemanha pós 1945); a «geração abatida» (Espanha pós-guerra civil); a «geração sofrida» (Itália, na II Guerra), para fazer referência a comportamentos decorrentes das sequelas da guerra. 
Porém, o crescimento econômico da Europa dos anos 1960, propagando valores de consumo, possibilitou o aparecimento de uma cultura juvenil como categoria autônoma, convertendo-se em idade da moda. Ao mesmo tempo, apareceu a imagem do «rebelde sem causa». Nos bairros de Londres, em 1976, após a explosão dos Sex Pistols, afirmou-se um novo estilo com os punks.

No ano de 1985, a ONU declara o Ano Mundial da Juventude, sinalizando que as coisas não iam muito bem. A desocupação juvenil, a ruína das ideologias, a fragilização do sentido da escola produziam uma atitude desencantada. Eram os «tempos das tribos», referidos por Michel Maffesoli.

No Brasil, acompanhando os movimentos mundiais, os jovens já foram, homogeneamente, definidos como «rebeldes», «geração paz e amor», «ousados e participativos», «geração perdida», «gangues», «caras-pintadas». Contemporaneamente, parece que a diversidade ganha mais visibilidade, dificultando que um grupo assuma a representação de todos. São tempos em que as fronteiras enfatizam as passagens, as hierarquias firmam as hibridizações e as oposições ressaltam as conexões. Como lembra Feixa (2004), viver a juventude já não é - como no complexo de Tarzan - transitar da natureza à cultura, nem tampouco - como no complexo de Peter Pan- resistir à vida adulta, mas experimentar o destino incerto - como no complexo do Replicante de Blade Runner, que se rebela porque não tem memória do passado- .

Serão os jovens deste início de século replicantes? Uma «geração @» que coloca o sentido da vida no presente, sem memória, sem consciência das possibilidades de projetar o futuro e transformar a vivência em experiência, como anuncia Benjamin (1996)? Ou, «programados» para utilizar as tecnologias, estão agora mais preparados para as mudanças? Com o fim das grandes utopias, são agora protagonistas de revoltas episódicas. Têm o mundo ao seu alcance, mas não são senhores de seus destinos.

Tal como em Blade Runner, os adultos vacilam entre o encanto pela juventude e a necessidade de exterminar tudo que ameaça a ordem e a norma. $\mathrm{O}$ resultado disso é um modelo híbrido e ambivalente de juventude, marcado pela dependência econômica, falta de espaço de responsabilização e um crescente amadurecimento intelectual que se expressa no acesso às tecnologias de informação e comunicação.

Em relação às tecnologias, é importante lembrar que uma parcela dos jovens de hoje são protagonistas culturais. São blogueiros, escrito- 
res, twiteiros, ficwriters, ${ }^{2}$ atividades de parcela significativa de jovens que não podem mais ser pensadas apenas como passatempo da fase juvenil. Essas experiências colocam os jovens na condição de autores e caracterizam uma geração que convive diariamente com orkut, youtube, facebook, google, ipods, MP6, ipads, pendrives, palmtop, blueray, tablets - lista que se atualiza a cada mês e aproxima juventude e mundo virtual-.

Ao manipular essas tecnologias, muitos jovens tornam-se protagonistas de ações que não são exclusivamente político-partidárias, mas pertencem a diferentes âmbitos, com acento na produção cultural. Como exemplo, destacam-se os campeonatos de basquete de rua; o dia da doação de sangue, organizado pelos jovens leitores d'O Senhor dos Anéis; bandas de garagem que cobram alimentos como ingresso em seus shows e depois organizam a distribuição entre grupos necessitados; ações para crianças de famílias de baixa renda organizadas por jovens de diferentes religiões; fanzineiros que criam uma ampla rede de comunicação alternativa sobre suas leituras, gostos musicais e literários; jovens escritores de fanfiction 3 que provocam mudanças também nos modos de ler, escrever e fazer circular textos-síntese de suas escritas virtuais. Que impactos isso tem provocado na compreensão que temos sobre jovens e participação? E como essas questões se manifestam na escola hoje?

$\mathrm{O}$ recurso a alguns estudos sobre o tema, apontando a diversidade das formas e conteúdos da participação dos jovens dessa geração, apresenta desafios à escola que busca maior aproximação com os sujeitos circulantes diariamente em seus espaços.

2 Ficwriters refere-se aos escritores de fanfic. Fanfic é a abreviação do termo em inglês fan fiction, ou seja, «ficção criada por fãs». São narrativas escritas por fãs do livro, filme, anime ou história em quadrinhos a que faz referência a fanfic.

3 Ver a tese de Larissa Camacho: Práticas de leitura e escrita na contemoraneidade: Jovens e Fanfictions, defendida em 2012 no PPEEDU/UFRGS. Este estudo evidencia práticas que vão na contramão dos discursos generalizantes da juventude contemporânea e apresenta jovens que leem muito, escrevem de forma colaborativa, interagem com seus leitores, produzem textos desafiados pelas histórias de que são fãs. A autora discute, assim, as implicações do advento da internet para a produção cultural dos jovens. 


\section{CONTORNOS DA PARTICIPAÇÃO JUVENIL CONTEMPORÂNEA}

A consolidação da democracia moderna, alicerçada na livre e direta manifestação da vontade do cidadão é, sem sombra de dúvida, um dos grandes acontecimentos do século XX. No entanto, sabe-se hoje que a promessa da modernidade não foi cumprida: o cidadão, ao contrário do que se imaginava, não teve sua emancipação, e continua tão preso quanto antes da idade da luz. Entretanto, seus medos, hoje, são outros: o desemprego, a exclusão, o desamparo.

No Brasil da década de 1970, começou a avançar o processo de democratização, com o surgimento de novos atores sociais e políticos, como as comunidades eclesiais de base, oposições sindicais, associações de bairros. Todos agiam articulados e colocavam no plano nacional a luta pelo reconhecimento dos direitos sociais, econômicos e políticos dos setores populares. Caccia-Bava indica que essa realidade aponta para a emergência de novos atores e outros modelos de desenvolvimento:

A manifestação de atores plurais na sociedade civil, intervindo nos processos de decisão política nacional e local, faz com que o debate tenha de levar em consideração a diversidade e pluralidade das demandas sociais e urbanas. $\mathrm{O}$ empobrecimento crescente e o encolhimento do Estado que nos diz respeito à extensão dos serviços públicos, colocam em destaque o tema do poder local e participação popular porque expressa uma dinâmica que traduz as questões centrais do cenário político nacional (Caccia-Bava, 1994:5).

Para desenhar este novo cenário político nacional, valoriza-se o discurso da participação popular, decorrente da falta de legitimidade atribuída aos governos que se sucederam, insensíveis à pobreza e à miséria de grande maioria da população. A participação popular trouxe para o cenário público novos atores, apresentados como uma realidade tangível, feita de fatos, vozes, conflitos, imagens, discussões e sentidos até então ausentes ou silenciados.

Nesse contexto, uma parcela dos jovens constitui diferentes formas de atuação. Rosana Reguillo (2003) refere-se às novas formas de participação juvenil a partir do contexto histórico e cultural em que estão situados hoje, ou seja, nesta densa atmosfera de desigualdades sociais, de forte influência dos meios de comunicação, de quebra das fronteiras tempo/espaço, mas, também, em um contexto de muitas possibilidades. Para a autora: 
Sus formas de organización han cambiado aceleradamente, de los cuadros del partido, de las células guerrilleras, de las organizaciones estudiantiles, de los bloques sindicalistas, han ido transitando hacia formas fluidas, itinerantes, intermitentes, que los vuelven más «temibles», pero al mismo tiempo, más vulnerables (Reguillo, 2003:1).

As palavras fluidas, itinerantes, intermitentes e vulneráveis, colocadas em evidência nesta citação, apontam novos enfoques para o tema da mobilização juvenil na contemporaneidade, aspectos referendados por estudos inicialmente empreendidos por Melucci $(1997,2001)$ e também por Serna (1997), Abramo (1997, 2004), Sposito (2000, 2003, 2005, 2007) Reguillo (2001, 2003), Novaes (2000, 2004, 2005).

Leslie Serna (1997), ao analisar a realidade mexicana e inspirada em Melucci, destaca as particularidades da participação juvenil no contexto do não emprego, da indústria cultural e da inserção dos jovens no narcotráfico, apontando para um novo paradigma da participação juvenil, pautado por quatro elementos: a novidade das causas de mobilização, a priorização da ação imediata, a importância do indivíduo na organização do movimento (é o centro das práticas, e o grupo não é mais um fim em si mesmo) e a ênfase na horizontalidade dos processos de coordenação. Para a autora (1997:49), «la participación juvenil se expresa hoy día en pequeños colectivos y grupos $\mathrm{y}$, muy claramente en acciones diversas en las que se participa de manera individual». Os jovens não querem perder sua individualidade na massa e estabelecem formas de participação social pouco ou nada institucionalizadas, o que lhes permite uma grande flexibilidade de atuação em campanhas específicas, em redes de informação e em ações concretas.

Em relação aos conteúdos, Serna (1997) destaca que a participação social está voltada para temas como democracia, direitos sexuais, equidade de gêneros, direitos humanos, direitos indígenas, paz e meio ambiente. Este último tem gerado um novo ator social, pois incorpora diferentes setores e classes com capacidade de ação em torno de assuntos concretos em âmbito local, ao mesmo tempo em que estabelece redes e coordenações, nacionais e internacionais. A autora enfatiza, ainda, que a participação juvenil na atualidade caracteriza-se pela diversidade e dispersão dos conteúdos e das formas de atuar, o que determina que a participação juvenil seja vista como um processo em constante transformação, pois os grupos, redes, movimentos, organizações nascem e morrem, renascem com novos nomes e propostas e esse contínuo recriar parece ir constituindo os jovens como atores sociais. 
Estudos realizados por Melucci $(1997,2001)$ são marcos relevantes a respeito da atuação juvenil na sociedade contemporânea. $\mathrm{O}$ autor rompe a visão dos movimentos sociais como ator único com plataforma de demandas homogêneas. Segundo ele, a estrutura centralizada, que caracterizou os movimentos sociais em outras décadas, não se manteve e os movimentos ambientalista, feminista e juvenil trazem formas emergentes de organização que são descentralizadas e horizontais. Resultam, portanto, de múltiplas redes de relações sociais entre sujeitos e associações civis.

Tendo em vista a diversidade de práticas políticas das juventudes, Melucci (1997:11-12) diz que, nas últimas décadas, «a juventude tem sido um dos atores centrais em diferentes ondas de mobilização coletiva», sejam ações empreendidas por jovens ou mobilizações que envolvem outras categorias sociais. $\mathrm{O}$ reconhecimento dos jovens como grupo social estratégico para ações coletivas e como sujeitos de direitos deu visibilidade ao movimento juvenil na construção de uma nova relação entre Estado e sociedade.

Outro aspecto importante nas reflexões de Melucci (2001) referese aos conceitos de latência e visibilidade, quando situam fenômenos coletivos na contemporaneidade. Os jovens e suas diversas formas de expressão sinalizam outros caminhos nas suas relações com a sociedade, cujo questionamento se coloca mais sobre as formas de representação e de organização dos sistemas políticos, nem sempre adequados aos novos atores.

O movimento pelo passe livre em Santa Catarina, ${ }^{4}$ constituiu exemplo das categorias de latência e visibilidade tratadas acima,

4 Em julho de 2004, a prefeitura de Florianópolis (SC) anunciou aumento de $15,6 \%$ nas passagens de ônibus e os estudantes fizeram a chamada Revolta da Catraca. Durante três semanas, houve manifestações, com estudantes pulando as catracas dos ônibus ou queimando maquetes de catracas em plena rua. Com o apoio da população, conseguiram impedir o aumento. Em 2005, os militantes de Florianópolis, que já faziam campanha pelo passe livre há 5 anos, convocaram uma plenária no V Fórum Social Mundial, em Porto Alegre, onde foi lançado oficialmente o Movimento Passe Livre (MPL), que «junta rebeldia com organização», segundo a jovem de São Paulo, Graziela Kunsch. Dali em diante, o movimento ganhou força e hoje atua em catorze cidades (Curitiba, Florianópolis, Fortaleza/ Maracanaú, Joinville, Rio Branco, Salvador, Santos, São Paulo, Campinas, Goiânia, Aracaju, Blumenau, Distrito Federal, Porto Alegre). 
quando os jovens apareceram na cena pública reivindicando a gratuidade do transporte coletivo para os estudantes. Numa abordagem superficial, o modo como se mobilizam e participam pode conduzir a formulações que os coloquem como alienados. Ao considerar as categorias de latência e visibilidade, no entanto, são anunciadas diferenciações dos processos de mobilização que os tornam atores estratégicos nas ações coletivas.

Segundo reportagem da revista Caros Amigos: ${ }^{5}$ «autônomos», «apartidários» e «independentes», como os próprios militantes do Passe Livre se definem. A eficácia da forma de organização horizontal é a grande novidade política que o MPL traz ao movimento estudantil. Hoje existem 20 coletivos espalhados por todo o país, e mais uma dezena de comitês estudando associação ao movimento. (2007).

Nesse episódio, os jovens falam não só aos estudantes. Eles reivindicam o benefício aos trabalhadores desempregados e, num segundo momento, a toda a população. As manifestações abrem o debate sobre a transformação do transporte coletivo urbano, criticam a concepção mercadológica e lutam pelo transporte público, gratuito e de qualidade, para o conjunto da sociedade.

Elementos da condição juvenil podem ativar uma mobilização conflitual que encontra eco em toda a sociedade. Os acontecimentos de maio de 2006, no Chile, ${ }^{6}$ foram, também, exemplo emblemático. Nas palavras de Gonzalo Martínez (2006:1) :

Hace dos años, CIDPA realizó un diagnóstico de la realidad juvenil en tres comunas de la quinta región, en donde nos señalaba que una gran cantidad de jóvenes no participaba en ninguna organización, y que no lo hacían debido a que ninguna institución los representaba. Ahora, dos años después, más de 800.000 jóvenes están movilizados en Chile y parti-

5 Reportagem disponível no site: http://carosamigos.terra.com.br/da_revista/edicoes/ed110/republica.asp.

6 Mobilização de estudantes, que apelam e interpelam o governo e a sociedade como um todo, por maiores níveis de "proteção social". São estudantes do ensino secundário que exigem da presidente Michelle Bachelet uma série de benefícios - entre os quais condução gratuita no sistema de transporte coletivo, exame vestibular gratuito para ingresso nas universidades do país, mudanças na jornada escolar, modernização dos colégios e reforma da Lei Orgânica de Ensino, instituída durante a ditadura militar-. O movimento vem ganhando amplo apoio de todos os setores e atores sociais e políticos e adquire legitimidade nas demandas, conteúdos e formas de atuação dos estudantes. 
cipando del movimiento secundario más grande en la historia nacional... parece que esto si que los representa.

Também nesse caso, os estudantes falaram em nome da sociedade. Parece que a mobilização dos estudantes pelo passe livre em Santa Catarina e dos secundaristas no Chile falam a «língua do possível [...] fazem exigência de decidir por eles próprios, mas com isto mesmo reivindicam para todos esses direitos» (Melucci, 2001:102). No caso do Chile, denunciam um sistema educacional herdado da ditadura e anunciam que é possível mudá-lo. Nas palavras de Dávila León (2006:4):

Em primeiro lugar convém assinalar que este movimento acirrou o mais amplo e unânime apoio de todos os setores e atores sociais e políticos (inclusive, em parte, da direita política, com outros fins). É a demanda por uma sociedade mais equitativa e justa, na qual os benefícios do crescimento cheguem a todos os chilenos. Ela se apresenta a nós como um tema de estratégias e táticas políticas de atuação, onde não se pode pedir aos jovens que eles sejam os transformadores do sistema educacional chileno. $\mathrm{O}$ grande resultado em si do movimento estudantil é ter apresentado o tema e que é possível mudá-lo, quando durante muitos anos não se tem tido a força ou a vontade de questionar o sistema educacional herdado da ditadura.

Recentemente, outros exemplos somam-se a esses: os jovens gregos, que se manifestaram contra o pacote de austeridade do governo, novamente os jovens chilenos, que exigem uma educação pública gratuita e de qualidade, os estudantes italianos, que mobilizaram, em 2011, uma greve geral para protestar contra o governo de Silvio Berlusconi, os jovens da Espanha, que realizaram a greve dos estudantes, com repercussão em mais 35 cidades espanholas, contra as medidas de austeridade que atingiram o ensino. No dia 15 de outubro de 2011, os jovens foram atores principais na jornada mundial de protesto contra os excessos da alta finança e a apropriação de recursos que lançam milhões de pessoas no desemprego e na pobreza. Cabe destacar também, que o ano de 2011 começou com uma série de revoltas populares protagonizadas por jovens dos países árabes, contra os regimes ditatoriais. Os momentos decisivos nas praças do Egito, Líbia, Tunísia, entre outros, tiveram jovens na linha de frente.

No Brasil, em outubro de 2011, os jovens protagonizaram, através das redes sociais, a Marcha contra a corrupção, que reuniu cerca de 20 mil pessoas apenas em Brasília. 
Todos os exemplos acima podem ser compreendidos a partir das categorias de latência e visibilidade propostas por Melucci (2001). A latência é uma espécie de laboratório submerso da inovação, que permite experimentar novos modelos sociais, trocar significados e códigos, sem muitas pressões da sociedade. Ela torna possível a visibilidade da ação porque a renova, produzindo novos significados para as mobilizações.

A latência e a visibilidade, associadas à atuação de parcela dos jovens hoje, instigam a reflexão sobre o papel do educador que precisa escutar os jovens e planejar ações pedagógicas articuladas com as características dessa geração. É um desafio exigente, que congrega os tempos da escuta com os tempos da formação, considerando que o ritmo interior - múltiplo e descontínuo -é diferente do ritmo da educação que cobra resultados mais imediatos-.

Conforme Helena Abramo, para além de uma «disposição sem engajamento», revelada por pesquisas quantitativas, há muitos jovens que participam efetivamente. Em vista disso, ela propõe construir novas perguntas e novos olhares para perceber a existência de diferentes formas de mobilização entre os jovens, que:

[...] vão desde a recusa passiva - postura que, mais que uma manifestação de apatia, contém a emissão de recados críticos à sociedade (que também pode ser interpretada como impugnação, como repulsa a um sistema do qual se sentem excluídos), até uma participação política que propõe mudanças (em movimentos estruturados, partidos, sindicatos etc.), passando pela participação individual ou grupal em organizações comunitárias, ou em torno dos mais diferentes tipos de causas, que podem ir das mais locais às mais planetárias, como voluntários em distintos tipos de atividades organizadas por diferentes tipos de instituições, participação em movimentos informais dos mais distintos tipos, em grupos de lazer, em movidas culturais, em «tribos», assim também, como já citamos, em formas violentas e destrutivas com relação à ordem e segurança social, como no caso das pandillas e algumas torcidas organizadas de esporte.

Assim, a participação juvenil hoje é plural, dispersa e fragmentada, tem uma capacidade de ação relacionada a um assunto concreto, não é institucionalizada, mas formada por redes vinculantes e flexíveis, estreitamente relacionados à cultura e à convivência. Assim, nos últimos vinte anos, têm crescido o estranhamento dos jovens frente às expressões políticas formais, que apontam outras formas de participação no espaço público. Para Reguillo (2003:11): 
Lo que esto quiere decir, es que las categorías de organización y participación deben también ser revisadas a la luz de los cambios en las expresiones juveniles; sí por un lado resulta fundamental mantener la mirada analítica y crítica sobre los procesos estructurales, es igualmente importante estudiar los territorios de la vida cotidiana, donde los sujetos jóvenes despliegan un conjunto de estrategias para resistir o negociar con el orden estructural. Se trata pues de mantener en tensión analítica la estructura y el sujeto, las formas de control y las formas de participación, el sistema y la vida cotidiana

É preciso considerar, portanto, a identificação afetiva e pessoal dos atores com as situações e motivos da participação. Na interseção entre o público e privado, emergem novas categorias que sustentam mobilizações diversas e pontuais e impõem a interrogação: estariam os jovens reinventando o mundo da participação com suas formas de ocupação do espaço público?

Regina Novaes e Christina Vital (2005) identificam quatro consignas mobilizadoras das juventudes hoje:

i) «Por uma sociedade ecologicamente sustentável», onde o ideário ecológico passou a ressignificar problemas, produzir sentimentos e motivar ações. Portanto, se existem poucos grêmios estudantis, parece haver, segundo as autoras, muitos grupos de jovens ambientalistas, por exemplo.

ii) «Pelo acesso à educação, ao trabalho e à comunicação nos moldes do século XXI». Situados numa sociedade com grande apelo ao consumo, jovens de diferentes classes sociais revelam pressa em trabalhar e conquistar emancipação financeira. Porém, estudos de Corrochano (2001, 2008), evidenciam que as dimensões do trabalho contêm diferentes sentidos para os jovens brasileiros. De modo geral, são: necessidade ou fonte de independência, possibilitando, inclusive, a própria vivência da condição juvenil, que oportuniza a realização pessoal.

Os movimentos juvenis reivindicam inclusão digital e escola de qualidade, que favoreça ao aquisição de saberes, valores e competências condizentes com o século XXI.

iii) «Pelo reconhecimento de demandas de grupos com vulnerabilidades específicas e pelo respeito à diferença». Jovens começam a participar levados por sentimentos gerados na vida privada e acabam por transformá-los em «lutas por direitos»;

iv) «Pela paz e pelo respeito aos direitos humanos». Jovens com histórias de vulnerabilidade social não só se tornam público-alvo das políticas públicas para a juventude, mas agentes de organizações voltadas para o combate à violência e ao tráfico. 
As considerações de Novaes e Vital apontam para novas formas de pertencimento social que permitem aos jovens expressar angústias, fazer denúncias e construir outras estratégias de participação. Não são mais estudantes, operários, camponeses e hippies lutando conta o capitalismo e as formas de ditadura, mas jovens em diferentes organizações que levantam as bandeiras da paz, dos direitos humanos, da proteção ambiental, da sustentabilidade e da inclusão social, entre tantas outras questões. Emergem desse processo juventudes diversas, com marcas geracionais comuns e demandas diversificadas.

É bastante provável que o exercício de outro olhar para as mobilizações da juventude faça emergir a criatividade que reinventa o mundo do trabalho, as ações solidárias; a indignação ética presente em alguns grupos juvenis e a valorização de temas ecológicos nas suas ações e projetos. Portanto, se alguns jovens destes tempos vivem o individualismo e consumismo, é possível identificar também outros elementos que impulsionam a participação, pensar nas virtualidades e possibilidades contraditórias presentes num mesmo processo.

Essa breve exposição dos estudos que analisam a participação juvenil também legitima considerar a diversidade de atores jovens presentes nas mobilizações; a emergência de novos temas, antes restritos às questões do crescimento econômico; a horizontalidade dos processos de organização e a tensão entre permanência e mudança das causas de mobilização. Em consequência, torna-se importante refletir a respeito do que tudo isso tem a ver com a escola.

\section{EDUCADORES E JOVENS: UM CASO DE AMOR MAL RESOLVIDO?}

Mudança é a palavra de ordem para compreender a escola e os educadores, os jovens e as juventudes nos tempos atuais. Não só as formas de mobilização e participação dos jovens vêm mudando. Os tempos também sofrem mutações profundas, afetando as instituições, a educação e a socialização das novas gerações. Outro modo de ser jovem coloca em questão práticas pedagógicas, espaços educativos e sistemas de autoridade, antes definidos pela tradição. Essas transformações às vezes distanciam educadores de jovens, colocando a escola como uma das instituições mais questionada pela sociedade.

São recorrentes as manifestações de professores acerca da quase impossibilidade de educarem jovens, especialmente do ensino médio. Excessos, transgressões, consumismo, apatia social, parecem prevalecer na fala de alguns educadores em relação aos seus jovens/alunos. 
Portanto, mais do que nunca, é preciso reinventar formas de proximidade entre os atores da educação. Mães e pais, professores e professoras procuram caminhos de entendimento, vacilam do excessivo ao muito pouco com testemunhos, frequentemente impróprios e pouco elucidativos. Conhecer sobre os modos de ser jovem hoje pode contribuir para a necessária aproximação entre alunos e educadores.

Os jovens que chegam às escolas hoje, são muito diferentes dos alunos de outros tempos. Diariamente os educadores de escolas públicas se deparam com jovens que, após dois meses de aulas, abandonam as salas, adquirem emprego ou se casam - ingressando na vida adulta- e, com a mesma rapidez, estão novamente desempregados, voltam à escola, se separam e redescobrem a condição juvenil.

Como pensar a escola para esses jovens, uma geração em que o «tempo flecha»se cruza com o «tempo cíclico» (Melucci, 2001), fazendo do tempo um eterno retorno? É possível construir uma escola onde a autonomia dos sujeitos não precise medir forças com a sujeição dos mesmos? Existe uma escola que se proponha a isso e obtenha sucesso? Provavelmente essa escola não exista em lugar nenhum. Entretanto, talvez ela esteja também em todos os lugares. Está dentro da própria escola, nos inúmeros movimentos cotidianos de jovens e educadores que interrogam a ordem escolar, reinventam espaços, tempos e culturas em seu interior. Está também fora dela: não apenas nos movimentos que reivindicam o direito à educação, mas também naqueles que afirmam, com suas ações e expressões, o direito a uma distribuição mais justa de conhecimento, cultura e cidadania.

Diante das dificuldades de inserção no mercado de trabalho, os jovens de camadas populares têm se mostrado céticos em relação à escola, desacreditando na obtenção do pleno emprego pela via educacional. $\mathrm{O}$ desencanto provém de uma situação real ligada às condições de vida e às impossibilidades a que estão submetidos.

Para muitos jovens, a escola é o espaço privilegiado de convivência. No entanto, a educação básica ainda não está efetivada como um direito de todos. Segundo dados do IBGE, em 2009, a taxa de frequência à escola, por jovens entre 15 e 19 anos, alcançou 85,2\%. Entre os jovens de 15 a 24 anos, quase 647 mil, 1,9\%, eram analfabetos. Os maiores decréscimos no analfabetismo por grupos etários, entre 1999 a 2009, ocorreram na faixa dos 15 aos 24 anos. Nesse grupo, as mulheres eram mais alfabetizadas, mas os homens apresentaram queda um pouco mais acentuada, passando de $13,5 \%$ para $6,3 \%$, contra $6,9 \%$ para $3,0 \%$ das mulheres. 
O problema não se resume ao acesso à escola, mas, principalmente, à qualidade do ensino na escola a que eles têm acesso. Frequentemente a escola está distante das juventudes e não responde às suas demandas, deixando de cumprir uma das suas funções centrais, que é promover e valorizar o diálogo entre as gerações.

Por que as mudanças nas formas de participação dos jovens podem ter impacto nas relações escolares? Primeiro porque é importante compreender que comparações estabelecidas entre diferentes gerações podem conduzir à formulação de vereditos conclusivos e equivocados. Os mais frequentes são: a juventude hoje é consumista, conservadora, alienada e não participativa em relação a outros tempos, como os jovens dos anos 60 e 70, que foram às ruas contra a ditadura civilmilitar. Não há informações confiáveis que permitam dizer que hoje existem mais ou menos jovens que participam de algum tipo de ação coletiva.. Atualmente estão em pauta novas questões e linguagens que renovam a mobilização e a participação dos jovens no espaço público. Diferente dos anos 60, em que o ator privilegiado era o estudante, hoje, é raro poder identificar, nas manifestações, um único grupo.

Novaes e Vital (2005:119) alertam que:

antes de evocar a crise das representações e decretar sua inexistência, apontando para a decadência do movimento estudantil, das juventudes partidárias e dos departamentos juvenis das organizações sindicais, é preciso perceber como esses processos têm sido afetados por novos temas e formas de organização com as quais são obrigados a conviver nos dias de hoje.

As formas institucionais de participação são possibilidades, entre tantas outras, para os jovens sentirem-se cidadãos ao fazer coisas. «Al decidir cuáles son las 'causas' en las que quieren involucrarse; al expresarse con libertad a través de distintos lenguajes» (Reguillo, 2003a:12), ao juntarem-se com outros jovens para construir, por exemplo, projetos culturais, percebem que esta experiência tem influência em outros âmbitos de suas vidas, o que os ajuda a imaginar projetos de futuro.

Quantas vezes a escola e seus profissionais insistem em reativar grêmios estudantis, denunciando a atitude não engajada dos jovens que freqüentam as escolas? Melucci (2001) anuncia que a agregação entre os jovens só é possível quando existe certa coincidência entre objetivos coletivos e necessidades afetivas, comunicativas e de solidariedade de cada um dos membros do coletivo. Pensar sobre isso pode auxiliar educadores a identificar aspectos das vivências de parti- 
cipação dos jovens, na escola ou fora dela, que indiquem tal coincidência. Ao se manterem presos às formas institucionais de participação (grêmios, diretórios, sindicatos e partidos) nem sempre se tornam perceptíveis aos professores outros jeitos de organização dos jovens/alunos, como os grupos que se formam por uma causa e, logo, se desfazem.

Alberto Melucci, José Machado Pais, Carlos Feixa, Máximo Canevacci, dentre outros, criticam o rótulo da chamada apatia política, atribuída aos jovens. Esses pesquisadores alertam para novas modalidades de inscrição juvenil no espaço público, nem sempre visíveis. Canevacci, em especial, faz críticas à ideia comum de associar jovens e consumo. Para o autor, a esfera do consumo reforça estereótipos impostos aos jovens que, sem trabalho, são impelidos a ampliar o tempo de vivência com os pais, como se valesse a sugestão: «Os jovens consomem, o adulto produz» (Canevacci, 2005:23).

Nesse sentido, cabe pensar nas possibilidades de a escola problematizar a sociedade de consumo e as estratégias do mercado, que capturam estilos e transformam o juvenil em modelo cultural.

\section{PARA CONTINUAR REFletindo}

Três possibilidades de síntese podem sinalizar a maior aproximação entre jovens e escola, especialmente do lugar do componente disciplinar de História.

\section{a) Os conteúdos de História e a história dos jovens}

Se, em outros momentos históricos, em especial as décadas de 60 e 70, o ensino de História contribuiu para a constituição de estudantes militantes e engajados politicamente, considerando que o espaço acadêmico apresentou leituras e propostas que serviram de âncoras teóricas para as ações dos movimentos estudantis desse período, também hoje a História ensinada e aprendida pode colaborar na organização de novas lutas e novos objetivos de mobilização. $\mathrm{O}$ grande desafio que está posto hoje ao ensino médio é o reconhecimento do aluno que existe por trás de estereótipos socialmente construídos, como os da apatia e da alienação.

Trata-se de aprofundar o diálogo entre o currículo de História e a história que diferentes jovens brasileiros fizeram e fazem: dos abolicionistas aos jovens que se organizam, por exemplo, no MST, no Mo- 
vimento Negro, no Fórum Social Mundial, nas redes sociais e tantos outros espaços. São histórias que dizem respeito aos jovens que circulam nas escolas brasileiras, a desafiar e questionar sistematicamente os educadores.

\section{b) Os conteúdos de História e as culturas juvenis}

A pluralidade cultural do mundo hoje se manifesta nos espaços sociais, inclusive nas escolas e nas salas de aula. Isso frequentemente acarreta confrontos e conflitos, tornando cada vez mais agudos os desafios a serem enfrentados pelos profissionais da educação. No ensino médio, a situação parece mais difícil com jovens que questionam continuamente o papel do professor e o sentido da escola. Nos estágios, acadêmicos defrontam-se com tais questões e percebem que ensinar História exige mais do que conhecimentos específicos. Muito há para indagar sobre quem são os jovens que circulam diariamente no espaço escolar. A distância entre os conteúdos de História e as vivências dos jovens fora do espaço escolar é evidenciada pelas tradicionais frases: «as aulas de História são chatas», «História é só passado», «temos que decorar muitas coisas. Isso cansa». «Em História muitas coisas não nos interessam. Data não é interessante e sempre tem um livro para decorar. Ficamos dormindo. A gente não tenta aprender, só decora para a hora da prova. É muito questionário». «Queremos aulas mais diversificadas, não só a fala do professor; relacionar o conteúdo com o que está acontecendo hoje». «O conteúdo parece que sempre é a mesma coisa. Queremos coisas mais atuais, mais informações do mundo».

Esses comentários dos jovens evidenciam questões que precisam ser repensadas no ensino de História, destacando a importância de os educadores conhecerem os jovens na concretude de suas existências, bem como a história da juventude, e indo além das construções da mídia e do mercado, que configuram interesses, estilos e comportamentos nem sempre caracterizadores dos jovens que povoam as salas de aula. Trata-se também de aceitar o desafio de planejar aulas, considerando os diferentes repertórios culturais dos alunos.

\section{c) Os cursos de formação de professores e as juventudes}

Há muita distância entre os conteúdos da formação de professores e os sujeitos jovens. A matriz curricular dos cursos de licenciatura, tanto nas universidades públicas quanto nas privadas, constitui-se a partir de 
um currículo que incide pouco sobre os sujeitos. Em algumas situações, os futuros professores terminam seus cursos sem uma formação que lhes possibilite conhecer seus alunos, ou, no mínimo, serem sensibilizados para a importância de conhecer os atores do processo educativo.

O anúncio dessas reflexões supõe uma aposta na escola como espaço de encontro, de trocas e de conhecimento entre jovens e educadores que vale a pena empreender.

PORTO ALEGRE (BRASIL), SEPTIEMBRE 2012

RECIBIDO: SEPTIEMBRE 2012

ACEPTADO: NOVIEMBRE 2012

\section{REFERENCIAS BIBLIOGRÁFICAS}

ABRAmo, Helena Wendel (2004): «Desejo de mudança e novas formas de participação». Disponível em: www.aracati.org.br.

— (1997): «Considerações sobre a tematização social da juventude». Revista Brasileira de Educação N5/6. São Paulo: ANPED.

— e PEDRo PAUlo MARTONI BRANCO (orgs.) (2005): Retratos da juventude brasileira: análises de uma pesquisa nacional. São Paulo: Instituto Cidadania e Editora Fundação Perseu Abramo.

Benjamin, WALTER (1996): O narrador. Considerações sobre a obra de Nikolai Leskov. Magia e técnica, arte e política. São Paulo: Brasiliense.

CACCIA-BAVA, Augusto e Dora IsAbel PAiva DA COSTA (2004): «O lugar dos jovens na história brasileira». In CACCIA-BAVA, FEIXA e GONZÁlEZ: Jovens na América Latina. São Paulo: Escritura Editora.

CACCIA-BAVA, Silvio (1994): «Democracia e poder local». In: RENATA VILlas-BOAS (org.): Participação popular nos governos locais. São Paulo: Polis.

Canevacci, Massimo (2005): Culturas extremas. Mutações juvenis nos corpos das metrópoles. Rio de Janeiro: DP\&A.

CARRANO, PAUlo (2002): Os jovens e a cidade: identidades e práticas culturais em Angra de tantos reis e rainhas. Rio de Janeiro: Relume Dumará, FAPERJ.

CORROCHANO, MARIA CARLA (2008): «O trabalho e a sua ausência: narrativas do programa Bolsa Trabalho no município de São Paulo». Programa de Pós-Graduação em Educação Universidade de São Paulo (tese de doutorado). (2001): «Jovens olhares sobre o trabalho: um estudo dos jovens operários e operárias de São Bernardo do Campo». Faculdade de Educação da Universidade de São Paulo (dissertação de mestrado). 
DÁVILA LEÓN, OSCAR (2006): «A rebelião dos pingüins». Instituto Humanitas Unisinos, Jornal On-Line.

FABBRINI, ANNA (1992): L'età dell'oro: adolescenti tra sogno ed esperienza. Milano: Feltrinelli.

FeiXA, CARles PÀmpols (2006): De jóvenes, bandas y tribus. Barcelona: Editorial Ariel.

(2004): «A construção histórica da juventude». In CACCIA-BAVA, FEIXA e GonZÁLEZ: Jovens na América Latina. São Paulo: Escritura Editora.

Gil, CARMem Zeli De VARGAS (2011): «Jovens e juventudes: consensos e desafios». Educação, Vol. 36, Nº1. Santa Maria.

(2004): «Juventude e contemporaneidade: limites e possibilidades». Última Década $\mathrm{N}^{\circ} 20$. Valparaíso: Ediciones CIDPA.

—- Nilton Bueno Fischer, Nilda Stecanela, Sueli Salva e Nara VIERA RAMOS (2007): «Narrativas juvenis em grupos de diálogos: nos conteúdos da experiência o significado da existência». Anais do VII RAM, Porto Alegre.

$\longrightarrow$ - - NARA VieIRA RAmos, Sueli SAlVA e Nilda STECANEla (2006): «Por uma política de direitos na educação». Revista Democracia Viva. Rio de Janeiro: Ibase.

LECCARDI, CARMEN (2005): «Por um novo significado do futuro: mudança social, jovens e tempo». Tempo Social, Vol. 17, N². São Paulo: USP.

MARGULIS, MARIO (1998): Viviendo a todas: jóvenes, territorios culturales y nuevas sensibilidades. Santafé de Bogotá: Siglo del Hombre Editores, Departamento de Investigaciones Universidad Central.

MARTÍNEZ, GonZALO (2006): «Nuevos tiempos, nuevos movimientos». Revista Electrónica Latinoamericana de Estudios sobre Juventud, Año 2, $\mathrm{N}^{\mathrm{o}}$ 3. www.joveneslac.org.

MeluCCI, AlBerto (2001a): A invenção do presente: movimentos sociais nas sociedades complexas. Rio de Janeiro: Vozes.

(2001b): «Silencio y voz juveniles. Individualidad y compromiso en la experiencia cotidiana de los adolescentes». Vivencia y Convivencia.

_ (1997): «Juventude, tempo e movimentos sociais». Revista Brasileira de Educação No5/6. São Paulo: ANPED.

_ (1996): «A experiência individual na sociedade planetária». Revista lua Nova N³8. São Paulo: CEDEC.

- (1994): «Movimentos sociais, renovação cultural e o papel do conhecimento: entrevista a Leonardo Avritzer e Timo Lyra». Novos Estudos CEPRAP Nº40. São Paulo: CEBRAP.

(1992): II gioco dell'io; il cambiamento di sè in una società global. Milano: Feltrinelli.

NovaES, REgINA (2000): «Juventude e participação social: apontamentos sobre a reinvenção da política». In ABRAMO, FREITAS e SPOSITO (orgs.): Juventude em debate. São Paulo: Cortez. 
e CRISTINA ViTAL (2005): «A juventude de hoje: (re)invenções da participação social». In ANDRÉS THOMPSON (org.): Associando-se à juventude para construir o futuro. São Paulo: Peirópolis.

e PAUlo VANUChI (orgs.) (2004): Juventude e sociedade: trabalho, educação, cultura e participação. São Paulo: Fundação Perseu Abramo.

PAIS, JOSÉ MACHADO (2001): Ganchos, tachos e biscates: jovens, trabalho e futuro. Porto: Âmbar.

_ (2003): Culturas juvenis. Lisboa: Imprensa Nacional Casa da Moeda.

Peralva, Angelina (1997): «O Jovem como modelo cultural». Revista Brasileira de Educação No5/6. São Paulo: ANPED.

Reguillo, RossanA (2003a): «Ciudadanías juveniles en América Latina». Última Década N¹9. Valparaíso: Ediciones CIDPA.

— (2003b): «Las culturas juveniles: um campo de estudio. Breve agenda para la discusión». Revista Brasileira de Educação №23. Belo Horizonte. (2001): «La gestión del futuro: contextos y políticas de representación». JÓVENES, Revista de Estudios sobre juventud Nº15. México: IMJ.

- (2000): Emergencia de culturas juveniles. Estrategias del desencanto. Buenos Aires: Grupo Editorial Norma.

SERNA, LESLIE (1997): «Globalización y participación juvenil». JóvENES, Revista de Estudios sobre juventud №5. México: IMJ.

SPOSITO, MARILIA PONTES (coord.) (2007a): Espaços públicos e tempos juvenil: um estudo de ações do poder público em cidades de regiões metropolitanas brasileiras. São Paulo: Global.

— (2007b): «Espaços públicos e tempos juvenil: diversidade e conflitos nas ações do poder público em cidades brasileiras». Anais do VII RAM, Porto Alegre.

(2005): «Algumas reflexões e muitas indagações sobre as relações entre juventude e escola no Brasil». In HELENA WENDEL ABRAMO e PEDRO PAUlO MARTONI BRANCO (orgs.) (2005): Retratos da juventude brasileira: análises de uma pesquisa nacional. São Paulo: Instituto Cidadania e Editora Fundação Perseu Abramo.

(1999): «Educação e juventude». Educação em Revista №29. Belo Horizonte: FEA/UFMG.

— e MARIA CARLA CORROCHANO (2005): «A face oculta da transferência de renda para jovens no Brasil». Tempo Social, Vol. 17, №2. São Paulo: USP.

— e SERGIO HADDAD (2004): Juventude, escolarização e poder local. São Paulo: FAPESP.

— e PAUlO CARRANO (2003): «Juventude e políticas públicas no Brasil». Revista Brasileira de Educação №24. Rio de Janeiro.

e ANGElinA PERALVA (org.) (1997): «Juventude e contemporaneidade». Revista Brasileira de Educação N5/6. São Paulo: ANPED. 